\title{
Synthesis of Mn-Doped Fe-MOFs with Different Ratios and Its Application for Photocatalytic Degradation of Rhodamine B Dye
}

\author{
Kim Ngan Thi Tran ${ }^{1,2^{*}}$, Thuy Bich Tran ${ }^{3}$, Sy Trung Do ${ }^{4}$, Kim Oanh Thi Nguyen ${ }^{1,2}$, and Tan Van Lam ${ }^{1,2^{* *}}$ \\ ${ }^{1}$ Institute of Environmental Sciences, Nguyen Tat Thanh University, Ho Chi Minh City, Vietnam \\ ${ }^{2}$ Faculty of Environmental and Food Engineering, Nguyen Tat Thanh University, Ho Chi Minh City, Vietnam \\ ${ }^{3}$ Institute of Environmental Science, Engineering and Management, Industrial University of Ho Chi Minh City, Vietnam \\ ${ }^{4}$ Institute of Chemistry, Vietnam Academy of Science and Technology (VAST), Hanoi City, Vietnam
}

\author{
*Corresponding author: \\ email:nganttk@ntt.edu.vn; \\ lvtan@ntt.edu.vn ${ }^{* *}$ \\ Received: July 19, 2021 \\ Accepted: September 27, 2021 \\ DOI: $10.22146 /$ ijc. 67742
}

\begin{abstract}
Recent trends in environmental remediation have shifted to the use of metalorganic framework (MOF) composites due to their unique structural properties. It is still challenging to diversify MOFs photocatalysts to fulfill application to treat toxic organic pigments. In this study, Fe-MOF bimetallic materials were synthesized by doping $\mathrm{Mn}^{2+}$ ions at different ratios. The structural and morphological characteristics of the materials were analyzed by XRD, UV-Vis, FT-IR, SEM, and UV-Vis DRS methods. Mn/Fe-MOF bimetallic organic framework materials were used to evaluate the photocatalytic degradation of Rhodamine $B(R h B)$ dyes. The results show that, under the same experimental conditions, the RhB degradation efficiency of $M n / F e-M O F$ is enhanced than that of the pristine Fe-MOF catalyst under the influence of visible light. After $120 \mathrm{~min}$, the $\mathrm{RhB}$ solution was decomposed to $91.78 \%$ by combining $0.1 \mathrm{Mn} / \mathrm{Fe}-\mathrm{MOF}, \mathrm{H}_{2} \mathrm{O}_{2}$, and visible light irradiation. At the same time, the presence of $\mathrm{H}_{2} \mathrm{O}_{2}$ in the reaction system also showed a strong impact on the efficiency of $\mathrm{RhB}$ degradation. The activity from the two metal centers of $\mathrm{Mn} / \mathrm{Fe}-\mathrm{MOF}$ contributes to the formation of a unique structure and composition that can be used as a photocatalyst for colored wastewater treatment.
\end{abstract}

Keywords: synthesis; bimetallic-organic framework; photocatalytic dye degradation

\section{- INTRODUCTION}

Behind the development, environmental pollution and pollution of toxic organic pigments are some of the urgent problems. Pollution of organic pigments directly affects people's life, health, and activities. Therefore, the treatment of wastewater right at factories and industrial parks is extremely necessary and requires a research investment. In treating toxic pigments, a low-cost catalyst, especially a high-efficiency and reusable one, is an effective and potential method.

In new material technology, Metal-Organic Frameworks (MOFs) are considered as one of the potential materials because of their stable structure, ability to contain functional groups essential for adsorption, porosity, large surface area, specificity, simple material fabrication process [1-3]. Currently, it is attracting much attention from researchers because of its potential application in the field of adsorption [4], catalysis [5-6], sensors [7], and drug delivery [8-9]. Recently, several MOFs with novel structures have been synthesized from two different metal centers and possess interesting photocatalytic properties. Some recent research results also indicate that small changes in the synthesis process can lead to different crystal structures. Specifically, Wang et al. (2020) carried out the synthesis of $\mathrm{Fe}_{\mathrm{x}} \mathrm{Co}_{\mathrm{y}} \mathrm{P}$ based on the change in the molar ratio of $\mathrm{Co} / \mathrm{Fe}$. As a result, the $\mathrm{FeCo}_{2} \mathrm{P}$ polyhedra have a controllable composition and morphology hollow structure and exhibits high electrocatalytic activity for the oxygen evolution reaction (OER) [10]. In another publication in 2020, Wu and co-workers significantly improved the adsorption and Fenton photodegradation 
for dyes (methylene blue, $\mathrm{MB}$, and methyl orange, $\mathrm{MO}$ ) of pristine $\mathrm{Fe}-\mathrm{BDC}$ by doping $\mathrm{Ni}$ into the $\mathrm{FeNi}_{\mathrm{x}}$-BDC frames at various ratios different [11].

The decrease in surface charges or pore volume and increased specific surface area is caused by secondary metal doping. For example, Kirchon et al. (2020) demonstrated markedly degraded removal efficiency of toxic organic compounds by partial substitution of $\mathrm{Mn}$ and Co for Fe in Fe-based MOFs. In which, 100\% of MB was decomposed by Fenton photocatalysis in the presence of PCN-250 $\left(\mathrm{Fe}_{2} \mathrm{Mn}\right)$ catalyst in less than $300 \mathrm{~min}$ [12].

Methods for synthesizing MOFs include precipitation, sol-gel, heat transfer, solvothermal, direct oxidation, physical or chemical evaporation, and ultrasonic methods [13-15]. However, these methods often exhibit limitations, such as high energy costs, many by-products, or low crystallinity of the resulting materials. In this study, we propose a solvothermal synthesis method with high efficiency and productivity.

Fe-based MOF materials with Mn were synthesized by the solvothermal method using DMF solvent and linked together by terephthalic acid as the organic ligand. The properties of $\mathrm{Mn} / \mathrm{Fe}-\mathrm{MOF}$, such as their size and porosity, change significantly when the synthesis rate is changed, leading to the change in the photocatalytic properties of the decomposition of the organic compounds. Furthermore, the difference in the material structure under the influence of different solvents leads to the change in the light absorption properties and affects the photocatalytic mechanism of the material. Thus, this study provides new insight into the enhanced photocatalytic activity of organic compounds' degradation of $\mathrm{Mn} / \mathrm{Fe}-\mathrm{MOF}$.

\section{- EXPERIMENTAL SECTION}

\section{Materials}

In this study, all chemicals used were supplied by the commercial company and are commercially available. Those include Iron(III) nitrate nonahydrate $\mathrm{Fe}\left(\mathrm{NO}_{3}\right)_{3} \cdot 9 \mathrm{H}_{2} \mathrm{O}$ (98.5\%, China), Manganese Chloride $\mathrm{MnCl}_{2} \cdot 6 \mathrm{H}_{2} \mathrm{O}$ (China 99\%), Terephthalic acid $\mathrm{H}_{2} \mathrm{BDC}$ (Sigma Aldrich 98\%), N,N-dimethylformamide DMF (China 99.5\%), Acetonitrile $\mathrm{CH}_{3} \mathrm{CN}$ (Merck, Germany
99.5\%), Methanol $\mathrm{CH}_{3} \mathrm{OH}$ (China), Rhodamine B $\mathrm{C}_{28} \mathrm{H}_{31} \mathrm{ClN}_{2} \mathrm{O}_{3}$ (Sigma Aldrich), and Hydrogen peroxide $\left(\mathrm{H}_{2} \mathrm{O}_{2}, 30 \%\right)$. The chemicals were used without further purification.

\section{Instrumentation}

The composites' formation and crystal phase change were determined by X-ray diffraction on $\mathrm{D} 8$ Advanced (Hitachi, Germany), with a wavelength $\lambda$ of $1.5406 \AA$ An Infrared spectroscopy (FT-IR) method was used to determine the presence of functional groups on the surface of materials by Nicolet 6700 (Thermo Fisher Scientific, USA) instrument with the wavelength in the range of $500-4000 \mathrm{~cm}^{-1}$. Scanning electron microscopy (SEM) method to determine the morphology and size of the material particles by S4800 series (JEOL, Japan). Diffuse reflectance spectroscopy can determine the absorption peaks of the catalysts and evaluate the change in bandgap energy $(\mathrm{Eg})$ values based on the Shimazu UV-2450 instrument with wavelengths from $200 \mathrm{~nm}$ to $1400 \mathrm{~nm}$. UV-Vis instrument (Aligent Cary 60, Malaysia) was used to determine the concentration of organic pigment solution during the photocatalytic activity assay of the material.

\section{Procedure}

The synthesis of Fe-MOF was carried out based on a previously published paper [16]. Specifically, a mixture of $\mathrm{Fe}\left(\mathrm{NO}_{3}\right)_{3} \cdot 9 \mathrm{H}_{2} \mathrm{O}(0.16 \mathrm{mmol})$ and $\mathrm{H}_{2} \mathrm{BDC}(0.18 \mathrm{mmol})$ was dissolved in $40 \mathrm{~mL}$ of $\mathrm{N}, \mathrm{N}$-dimethylformamide (DMF). Next, $40 \mathrm{~mL}$ of $\mathrm{CH}_{3} \mathrm{CN}$ was added to the homogenizing stirring solution for $30 \mathrm{~min}$ at room temperature. The reaction was carried out in a $100 \mathrm{~mL}$ Teflon sample container with a stainless steel protective cover and heated at $150{ }^{\circ} \mathrm{C}$ for $12 \mathrm{~h}$ in the reactor. After the reaction was completed, the reaction mixture was allowed to cool naturally to room temperature. Then wash the reaction mixture with DMF (3 times) and methanol (3 times), respectively. Finally, the obtained material was dried at $150{ }^{\circ} \mathrm{C}$ under vacuum for $12 \mathrm{~h}$. Similarly, samples of Fe-MOF bimetallic materials were further synthesized by doping $\mathrm{Mn}^{2+}$ ions at the selected $\mathrm{Mn}^{2+} / \mathrm{Fe}^{3+}$ molar ratios of $0.05,0.1,0.3$, and 0.5 . The appropriate proportion of denatured samples was 
selected based on the structure and morphology to carry out the photocatalytic degradation of Rhodamine $B$ (RhB).

The photocatalytic reaction was carried out through the ability to decompose RhB under a $40 \mathrm{~W}$ LED irradiation, and the solution was stirred continuously at $500 \mathrm{rpm}$. RhB concentrations were analyzed using a UVVis spectrophotometer at a maximum absorption wavelength $\lambda=554 \mathrm{~nm}$. All Mn/Fe-MOF doped samples at different molar ratios were photoactivated through a reaction system in a heat-resistant beaker $(250 \mathrm{~mL})$ containing $100 \mathrm{~mL}$ of $\mathrm{RhB}$ solution with concentrations of $3 \times 10^{-5} \mathrm{M}$ and $5 \mathrm{mg}$ of the adsorbent [17]. The reaction mixture was stirred on a magnetic stirrer for 60 min until adsorption equilibrium was reached. Then, $4 \mathrm{~mL}$ of the mixture was taken out, centrifugated the solids, and measured the absorbance $(t=0)$. Next, $1 \mathrm{~mL}$ of $\mathrm{H}_{2} \mathrm{O}_{2}(1$ $\mathrm{mM}$ ) was added, and the solution began to be illuminated. After a certain period, $4 \mathrm{~mL}$ of sample solution will be taken out until the $120 \mathrm{~min}$ is up. Finally, UV-Vis absorption analysis was conducted to evaluate the concentration of the RhB solution through the decrease in color concentration, expressed by the change in the maximum absorption peak intensity under the effect of light.

\section{- RESULTS AND DISCUSSION}

\section{Characterization}

XRD was used to examine the composition and crystal phase growth of samples of Fe-MOFs modified with $\mathrm{Mn}$ at different $\mathrm{Mn}$ : Fe molar ratios of $0.05,0.1,0.3$, and 0.5. The XRD results showed that the Fe-MOF sample showed characteristic diffraction peaks at $2 \theta$ of $11.42^{\circ}$; $18.13^{\circ} ; 19.38^{\circ}$ corresponded to the study of Sun et al. and compared with simulated spectrum (CCDC 1892483) [18]. In addition, the crystalline characteristics of the three samples of $\mathrm{Mn} / \mathrm{Fe}-\mathrm{MOF}$ bimetallic materials are shown more specifically in Fig. 1. X-ray diffraction (XRD) analysis of the three Mn-modified Fe-MOF samples all shows similar characteristic peaks, indicating that they have nearly identical crystal structures, although with some slight differences in the peak intensity. However, magnifying at about $10^{\circ}-20^{\circ}$, the diffraction peak of about

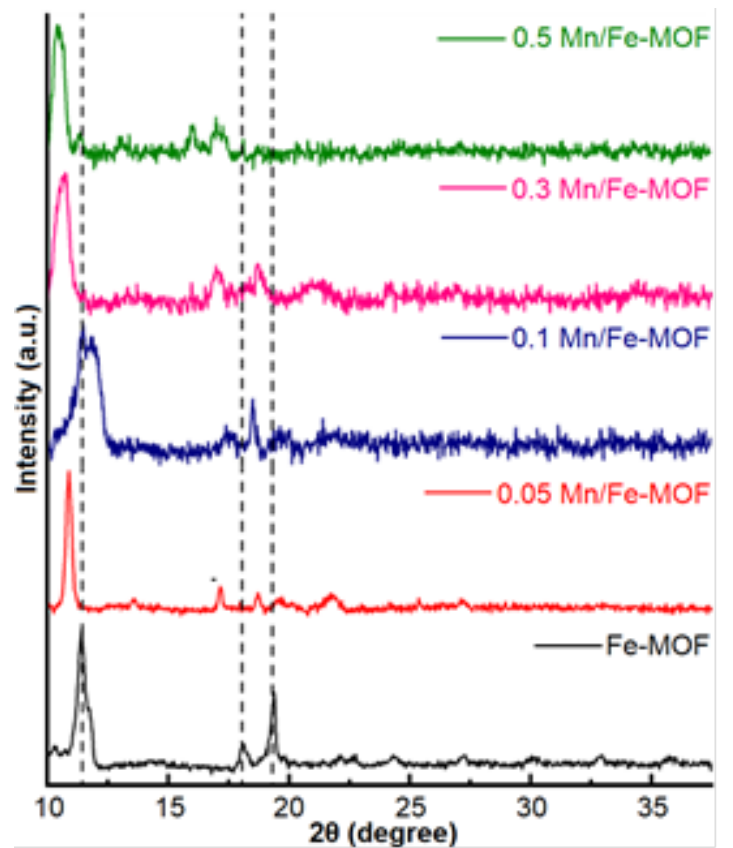

Fig 1. XRD spectrum of $\mathrm{Mn} / \mathrm{Fe}-\mathrm{MOF}$ at different ratios

$11.42^{\circ}$ is slightly shifted to a lower angle as the molar ratio of $\mathrm{Mn} / \mathrm{Fe}$ increases, while the opposite trend with $0.1 \mathrm{Mn} / \mathrm{Fe}-\mathrm{MOF}$ molar ratio has a clear shift towards a higher angle. The modified sample with $\mathrm{Mn}^{2+}$ broke the structure of Fe-MOF, the diffraction peaks characteristic of the Fe-MOF frame almost disappeared. The competition for electron affinity between the two ions and the significant difference in ionic radii between $\mathrm{Mn}^{2+}$ and $\mathrm{Fe}^{3+}\left(\mathrm{Fe}^{3+}=0.64 \AA, \mathrm{Mn}^{2+}=0.75 \AA\right)$ lead to the deformation of the original material structure. On the other hand, due to the flexibility or breathing effect of the Fe-MOF construct [19-20].

The infrared spectrum of Fe-MOF materials is presented in Fig. 2. It can be seen that the absorption bands with wavenumbers of 1594, 1390, 1396, and $750 \mathrm{~cm}^{-1}$ are typical for the vibrations of the carboxylate group of Fe-MOF. The absorption band at a wavenumber of $3093.3 \mathrm{~cm}^{-1}$ (strong) indicates the $\mathrm{O}-\mathrm{H}$ group's existence in the structure's water molecules. The absorption band at wavenumbers of 1593.8 and $1389.5 \mathrm{~cm}^{-1}$ are typical for the symmetric and asymmetric valence vibrations of the carboxylic group of BDC coordinated with the central metal, demonstrating that, in the sample, there is a formation into a dicarboxylate group bond. The absorption band at a wavenumber of 

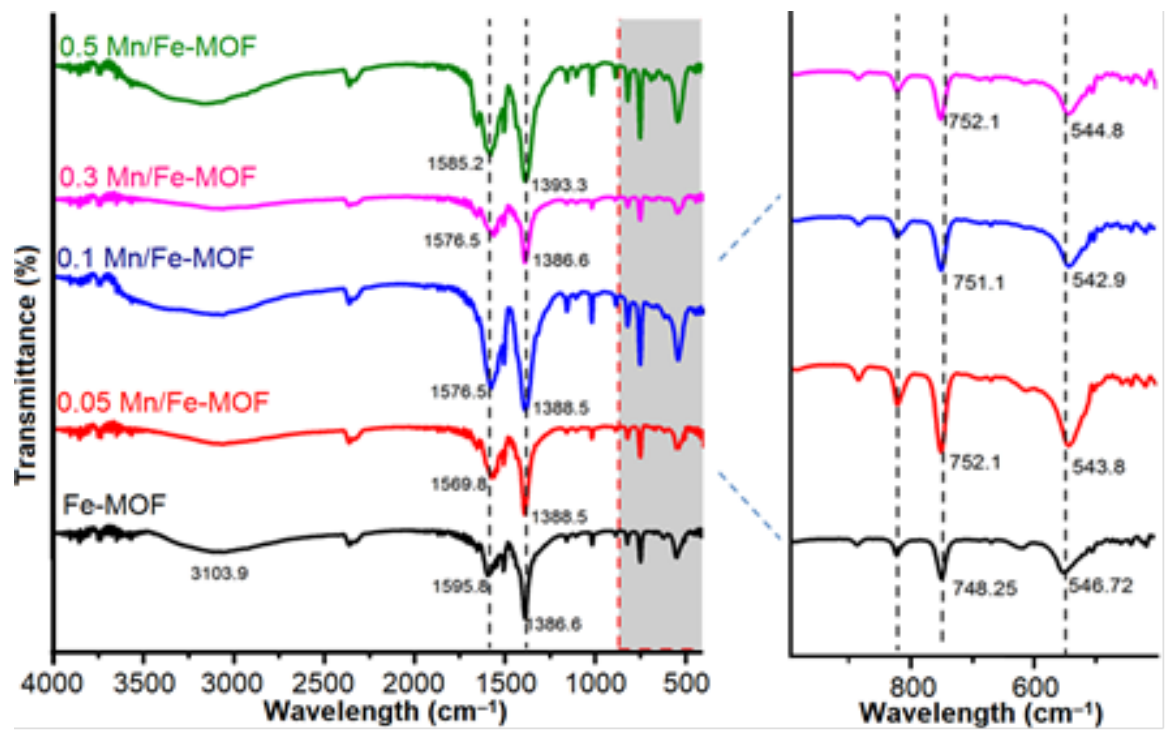

Fig 2. FTIR spectrum of $\mathrm{Mn} / \mathrm{Fe}-\mathrm{MOF}$ at different ratios

$750 \mathrm{~cm}^{-1}$ confirms the benzene ring's $\mathrm{C}-\mathrm{H}$ bond vibration. The absorption band at wave number $552 \mathrm{~cm}^{-1}$ is characteristic of the $\mathrm{Fe}-\mathrm{O}$ bond covalent vibration. When modifying Fe-MOF with Mn, the FTIR spectrum of the material still shows the characteristic peaks of FeMOF, no apparent change in the structure of the material is observed on the FTIR spectrum.
Fig. 3 surface morphology of Fe-MOFs observed by SEM shows that the typical grain size of Fe-MOFs is mainly the formation of well-defined homogeneous hexagonal bars with pointed tips. However, the shape and size of the Fe-MOF modified materials are highly dependent on the $\mathrm{Mn} / \mathrm{Fe}$ molar ratio. The increased $\mathrm{Mn}$ doping makes the morphology of bimetallic MOFs more
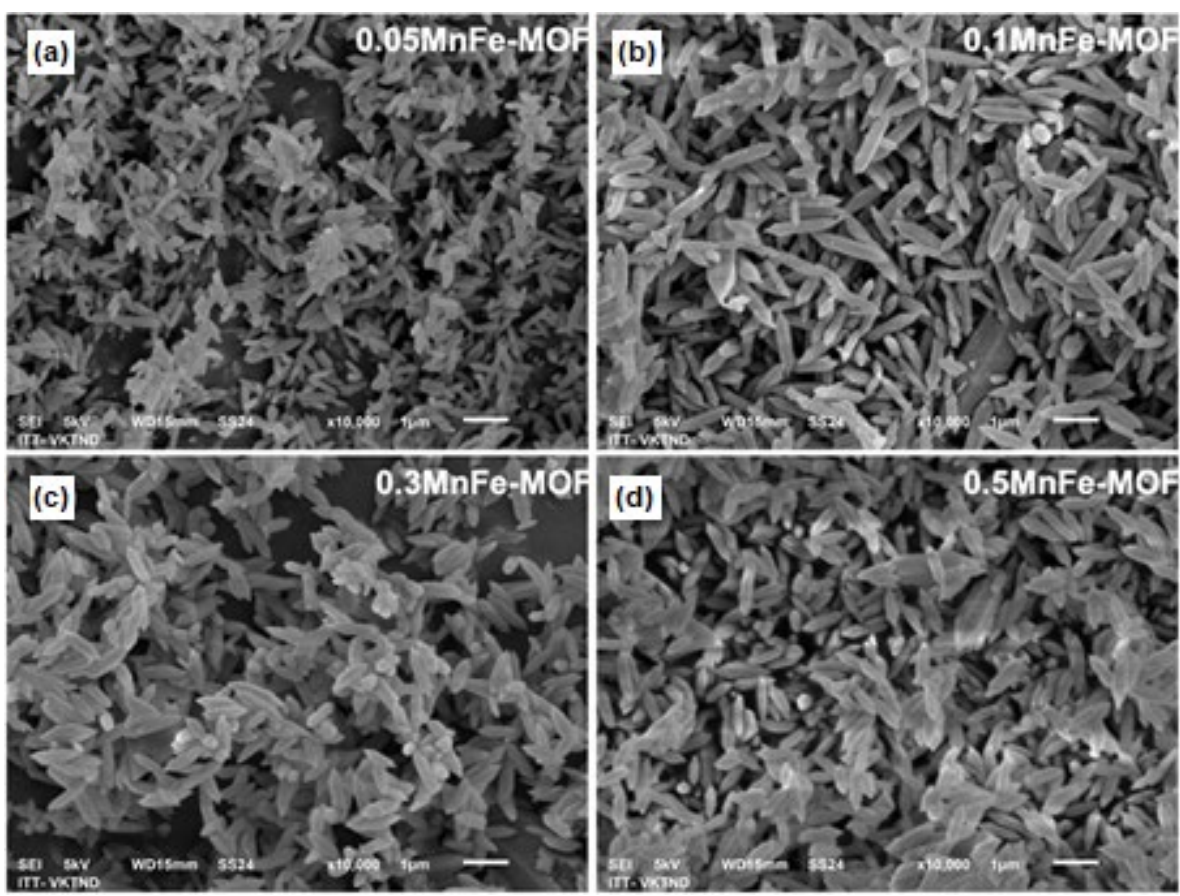

Fig 3. SEM images of Mn/Fe-MOF materials: (a) $0.05 \mathrm{Mn} / \mathrm{Fe}-\mathrm{MOF}$, (b) $0.1 \mathrm{Mn} / \mathrm{Fe}-\mathrm{MOF}$, (c) $0.3 \mathrm{Mn} / \mathrm{Fe}-\mathrm{MOF}$ and (d) $0.5 \mathrm{Mn} / \mathrm{Fe}-\mathrm{MOF}$ 
regular but significantly different. The surface morphology and shape of the $\mathrm{Mn} / \mathrm{Fe}-\mathrm{MOF}$ materials were studied through SEM images. The results show a clear change in the shape and size of the material when changing the ratio of $\mathrm{Mn}^{2+} / \mathrm{Fe}^{3+}$. In the sample of 0.05 $\mathrm{Mn} / \mathrm{Fe}-\mathrm{MOF}$, heterogeneous particles with different shapes and sizes appeared. When increasing the ratio of $0.1 \mathrm{Mn} / \mathrm{Fe}-\mathrm{MOF}$, the particles are uniform in size and shape. However, as the ratio increases, the size uniformity decreases, the grain shape begins to lengthen and stick together. Hence, the size of the crystals is larger at the ratio of $0.3 \mathrm{Mn} / \mathrm{Fe}-\mathrm{MOF}$ and $0.5 \mathrm{Mn} / \mathrm{Fe}-\mathrm{MOF}$.

The UV-Vis diffuse reflectance spectroscopy (DRS) method was used to determine the light absorption characteristics of the bimetallic $\mathrm{Mn} / \mathrm{Fe}-\mathrm{MOF}$, and the corresponding results are depicted in Fig. 4. The UV-Vis DRS results demonstrate the successful doping of Mn into the Fe-MOF lattice of the materials. Samples of composites at different scales give different bandgap energy values. The bandgap energy of Fe-MOF narrowed after $\mathrm{Mn}$ doping in the ratio of Fe-MOF, from 2.81 to $2.79 \mathrm{eV}$ of $0.05 \mathrm{Mn} / \mathrm{Fe}-\mathrm{MOF}, 2.77 \mathrm{eV}$ of $0.1 \mathrm{Mn} / \mathrm{Fe}-\mathrm{MOF}, 2.67 \mathrm{eV}$ of $0.3 \mathrm{Mn} / \mathrm{Fe}-\mathrm{MOF} \mathrm{eV}$, and $2.66 \mathrm{eV}$ of $0.5 \mathrm{Mn} / \mathrm{Fe}-\mathrm{MOF}$ samples, respectively. This difference is explained by the more efficient separation of the excited electron pairs supported by the second metal ion in the MOF lattice.
Some previously published results indicate a helical d-d transition $([6 \mathrm{Alg} \rightarrow 4 \mathrm{Alg}+4 \mathrm{Eg}(\mathrm{G})])$ of $\mathrm{Fe}^{3+}$ in MOFs [21-22]. However, the presence of a second metal ion, in addition to helping to disperse the Fe-MOF crystals evenly, creates small-sized particles. The second metal ion plays a crucial role in receiving electrons from the conduction band of MOFs photocatalysts, reducing and limiting the recombination between electrons and the $\mathrm{h}^{+}$ hole, thus effectively increasing the catalytic activity.

\section{Photocatalytic Activity}

The photocatalytic activity of the material was evaluated on the decomposition reaction of $\mathrm{RhB}$ organic pigment using visible light through experiments [23]. Experimental conditions were fixed at $\mathrm{RhB}$ concentration of $3 \times 10^{-5} \mathrm{M}$, catalyst weight of $5 \mathrm{mg}$, solution $\mathrm{pH} 5$, and $\mathrm{H}_{2} \mathrm{O}_{2}$ concentration of $10^{-3} \mathrm{M}$. The results of photocatalytic degradation reaction of $\mathrm{RhB}$ on Fe-MOF samples and samples modified with $\mathrm{Mn}^{2+}$ at different ratios are presented in Fig. 5(a). The RhB dye was removed up to $85 \%$ in $120 \mathrm{~min}$ by the presence of $\mathrm{Fe}-\mathrm{MOF} / \mathrm{H}_{2} \mathrm{O}_{2}$. However, the decrease in $\mathrm{RhB}$ concentration was evident when using Fe-MOF modified with $\mathrm{Mn}$ at different $\mathrm{nMn}^{2+} / \mathrm{nFe}^{3+}$ ratios. The results showed that the sample denatured at the ratio $\mathrm{Mn}^{2+} / \mathrm{Fe}^{3+}$ of 0.1 results in the best catalytic activity with
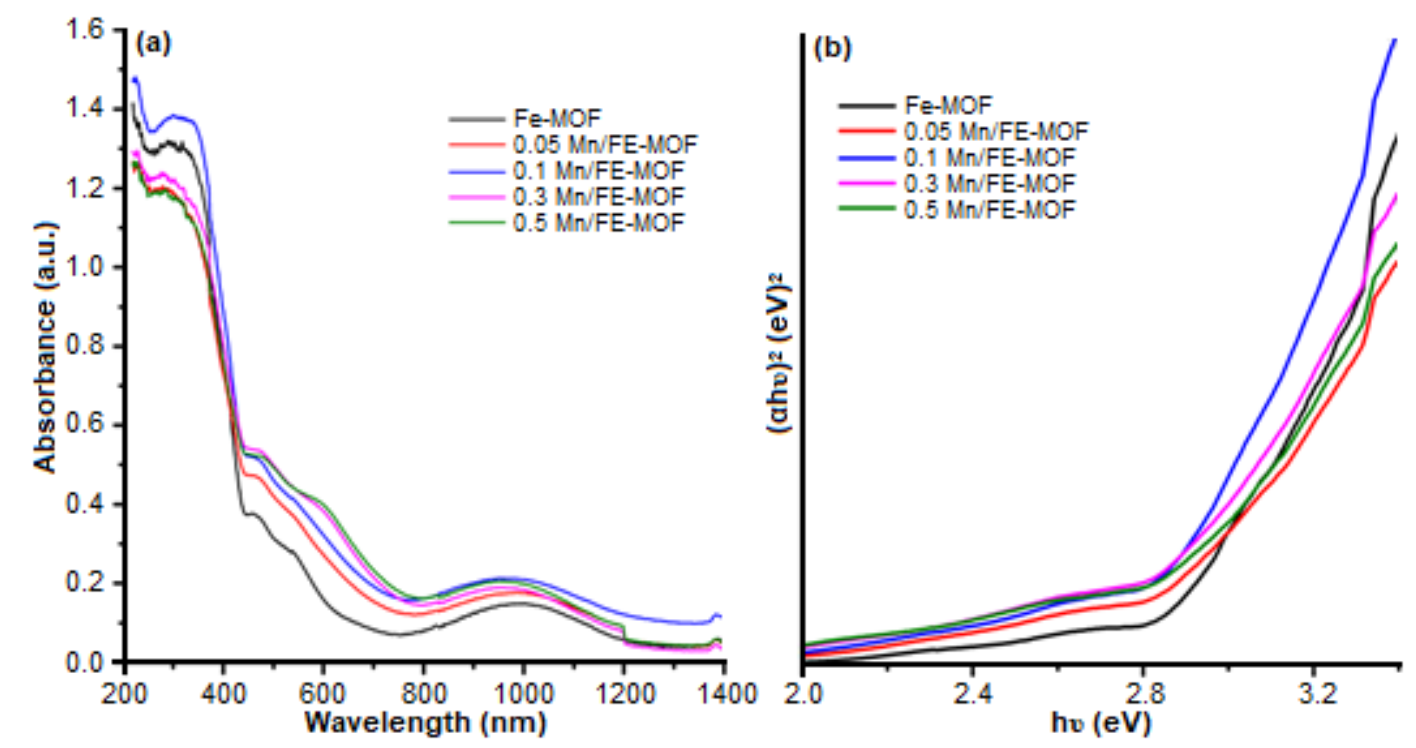

Fig 4. UV-Vis DRS plot (a) and bandgap energy (b) of Mn/Fe-MOF at different ratios 

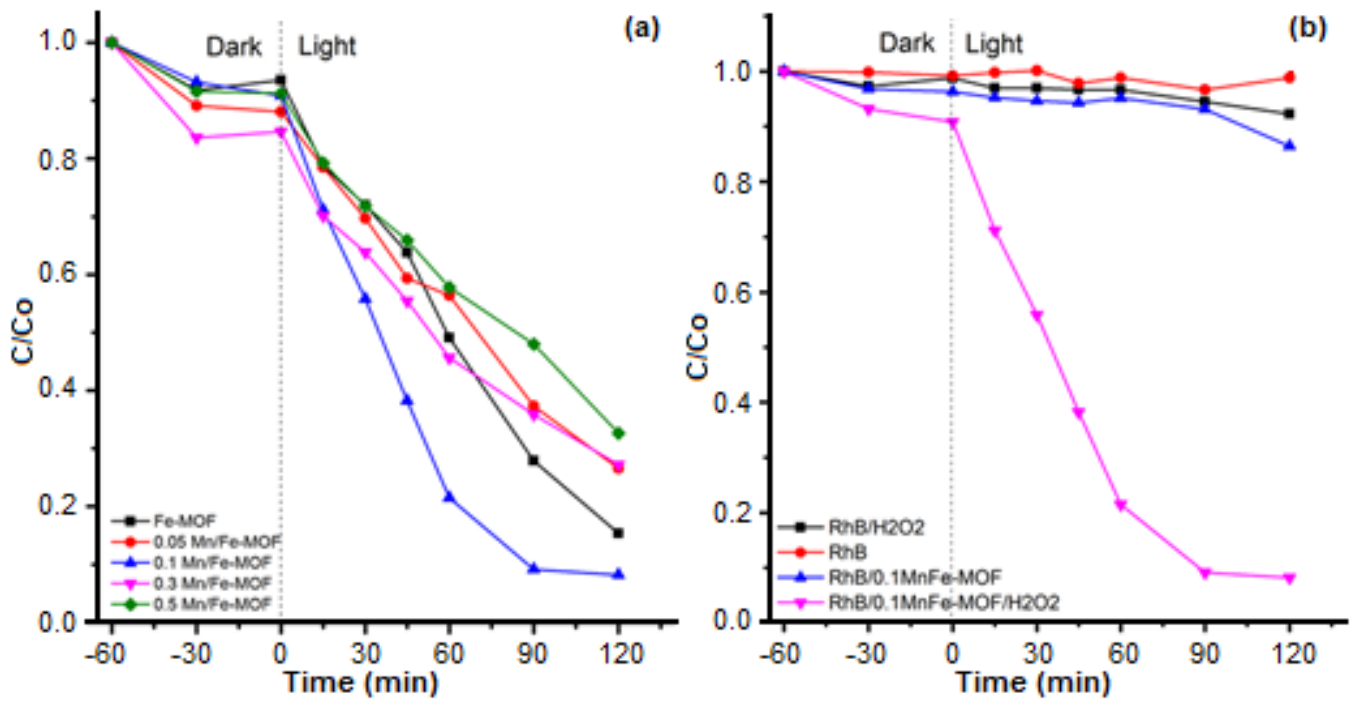

Fig 5. Photocatalysis of RhB decomposition of $\mathrm{Mn} / \mathrm{Fe}-\mathrm{MOF}$ at different rates

$91.78 \%$ after $120 \mathrm{~min}$ of illumination. Then it followed by $\mathrm{Mn}^{2+} / \mathrm{Fe}^{3+}$ of 0.05 (73.41\%), and $\mathrm{Mn}^{2+} / \mathrm{Fe}^{3+}$ of 0.3 (72.82\%). Meanwhile, the lowest sample was $\mathrm{Mn}^{2+} / \mathrm{Fe}^{3+}$ of $0.5(67.38 \%)$.

Partial substitution of the metal center of MOFs can enhance the photocatalytic activity under visible light, introducing new energy levels leading to metal-to-metal charge transfer, which will improve MOF photocatalytic activity. Recently, the study by Wu et al. (2020) showed that in a heterogeneous Fenton-like system, the catalytic performance of $\mathrm{FeNi}_{\mathrm{x}}$ - $\mathrm{BDC}$ is derived from the active sites of $\mathrm{Fe}$ in the lattice framework, determining oxidation capacity and reaction rate of the system. Therefore, the more Ni replaces Fe in the lattice framework, the worse the catalytic performance of bimetallic MOFs [11]. In addition, Sun et al. (2016) describe the partial isomer substitution of iron in the Fe metal-organic framework (BDC) with $\mathrm{Mn}, \mathrm{Co}$, and Ni. The catalytic performance of these materials was examined in the decomposition of phenol at $35^{\circ} \mathrm{C}$ and a near-neutral $\mathrm{pH}$ of 6.2. The results show that the degradation efficiency can be clearly improved by incorporating $\mathrm{Mn}$. Furthermore, the $\mathrm{n}(\mathrm{Fe}) / \mathrm{n}(\mathrm{Mn})$ ratio in bimetallic MOFs has a strong impact on the decomposition process [18].

Fig. 5(b) shows that $\mathrm{H}_{2} \mathrm{O}_{2}$ affects the degradation of RhB dye. When adding $\mathrm{H}_{2} \mathrm{O}_{2}$ to the reaction, combined with the catalyst under lamp irradiation, the $\mathrm{RhB}$ decomposition reached $92 \%$ within 120 min, and the $\mathrm{RhB}$ decomposition took place faster. The photocatalytic activities were carried out under conditions containing only ( $\mathrm{RhB}$ and light) or $\left(\mathrm{RhB}, \mathrm{H}_{2} \mathrm{O}_{2}\right.$, and light). The $\mathrm{RhB}$ color degradation efficiency was only less than $5 \%$, and the efficiency reached $10 \%$ in the presence of $0.1 \mathrm{Mn} / \mathrm{Fe}$ MOF catalyst but without the support of hydrogen peroxide. It can be explained by the fact that $\mathrm{OH}^{\cdot}$ radicals from $\mathrm{H}_{2} \mathrm{O}_{2}$ are generated much, promoting the reaction process, leading to an increase in the rate and efficiency of decomposition.

The efficiency of RhB removal in photochemical reaction by $0.1 \mathrm{Mn} / \mathrm{Fe}-\mathrm{MOF}$ catalyst is shown by the light absorption intensity in the UV-Vis spectrum in Fig. 6 . When the irradiation time was increased, the intensity of the characteristic peaks of $\mathrm{RhB}$ at $554 \mathrm{~nm}$ decreased suddenly. The pink color of the solution completely disappeared after $120 \mathrm{~min}$ of irradiation, indicating that the irradiation process photocatalytic effect destroyed the chromophoric structure of the $\mathrm{RhB}$ dye. The $\mathrm{RhB}$ color degradation of $0.1 \mathrm{Mn} / \mathrm{Fe}-\mathrm{MOF}$ gives a high efficiency of Fe-MOF in 120 min of illumination. During $\mathrm{RhB}$ degradation, the absorption peak of $\mathrm{RhB}$ decreases in intensity or shifts to a lower wavelength (hypsochromic) or can remain at the same wavelength $(554 \mathrm{~nm})$ with increasing irradiation time. On the other hand, the $\mathrm{N}$-deethylation degradation mechanism and the formation of a series of $\mathrm{N}$-deethylated intermediates lead to a peak left-shift (blueshift) of the absorption peak 

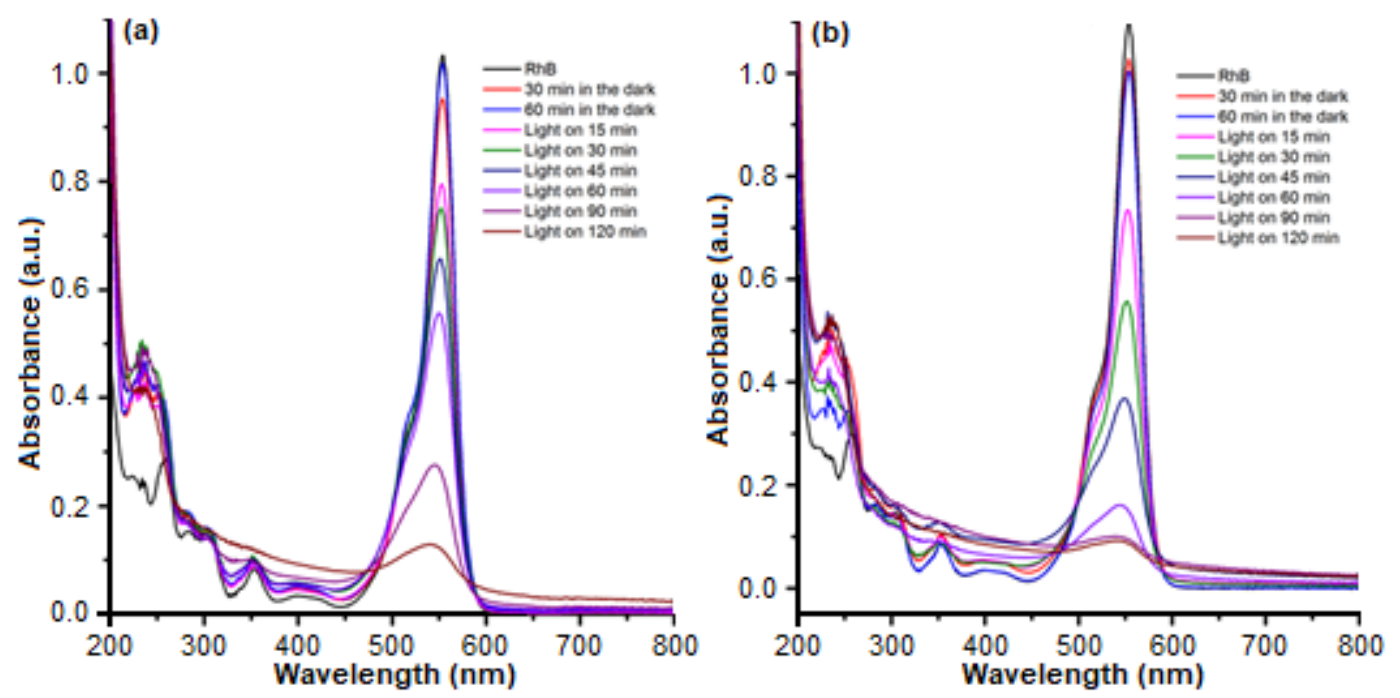

Fig 6. The absorption spectrum of $\mathrm{RhB}$ on Fe-MOF (a) and $0.1 \mathrm{Mn} / \mathrm{Fe}-\mathrm{MOF}$ (b) catalyst

of RhB. The results show that the $0.1 \mathrm{Mn} / \mathrm{Fe}-\mathrm{MOF}$ material has strong activity and can be used as a photocatalyst for potential practical applications [24].

\section{- CONCLUSION}

In summary, we have successfully synthesized FeMOF bimetallic materials with doped molar ratios of $\mathrm{Mn} / \mathrm{Fe}$ by the solvothermal method. The material characteristics of SEM, UV-Vis DRS, XRD, FT-IR, and $\mathrm{UV}$-Vis materials have shown that the material has a very high order. The crystals have a uniform octahedral morphology and high crystallinity. The results indicated that the molar ratio of $0.1 \mathrm{Mn} / \mathrm{Fe}$ showed excellent photocatalytic activities and durability when removing organic pollutants under visible light irradiation. The 0.1 $\mathrm{Mn} / \mathrm{Fe}-\mathrm{MOF}$ material gave the highest catalytic activity with $\mathrm{RhB}$ conversion of $91.78 \%$ after $120 \mathrm{~min}$ of illumination in the following conditions: initial $\mathrm{RhB}$ concentration was $3 \times 10^{-5} \mathrm{M}$; catalyst amount is $5 \mathrm{mg} ; 1$ $\mathrm{mL} \mathrm{H}_{2} \mathrm{O}_{2}(1 \mathrm{mM})$ and $\mathrm{pH}$ 5. The doping of the second metal in the lattice framework of MOF significantly improved the photocatalytic degradation activity, and the reaction was also more stable than that of the catalyst pristine Fe-MOF. This result opens the possibility of applying photocatalytic decomposition in the treatment of the toxic organic matter.

\section{- ACKNOWLEDGMENTS}

This study was supported by grants from Nguyen Tat Thanh University, Ho Chi Minh City, Vietnam.

\section{- REFERENCES}

[1] Furukawa, H., Cordova, K.E., O'Keeffe, M., and Yaghi, O.M., 2013, The chemistry and applications of metal-organic frameworks, Science, 341 (6149), 1230444.

[2] Shekhah, O., Wang, H., Zacher, D., Fischer, R.A., and Wöll, C., 2009, Growth mechanism of metalorganic frameworks: Insights into the nucleation by employing a step-by-step route, Angew. Chem. Int. Ed., 48 (27), 5038-5041.

[3] Dey, C., Kundu, T., Biswal, B.P., Mallick, A., and Banerjee, R., 2014, Crystalline metal-organic frameworks (MOFs): Synthesis, structure and function, Acta Crystallogr., Sect. B: Struct. Sci., Cryst. Eng. Mater., 70, 3-10.

[4] Akhbari, K., and Morsali, A., 2015, Needle-like hematite nano-structure prepared by directed thermolysis of MIL-53 nano-structure with enhanced methane storage capacity, Mater. Lett., 141, 315-318.

[5] George, P., Dhabarde, N.R., and Chowdhury, P., 2017, Rapid synthesis of Titanium-based metalorganic framework (MIL-125) via microwave route 
and its performance evaluation in photocatalysis, Mater. Lett., 186, 151-154.

[6] Yu, B., Wang, F., Dong, W., Hou, J., Lu, P., and Gong, J., 2015, Self-template synthesis of core-shell ZnO@ZIF-8 nanospheres and the photocatalysis under UV irradiation, Mater. Lett., 156, 50-53.

[7] Liu, J., Hou, J.X., Gao, J.P., Liu, J.M., Jing, X., Li, L.J., and Du, J.L., 2019, Stable Cd(II)-MOF as a fluorescent sensor for efficient detection of uranyl ions, Mater. Lett., 241, 184-186.

[8] Jiang, K., Zhang, L., Hu, Q., Yang, Y., Lin, W., Cui, Y., Yang, Y., and Qian, G., 2018, A biocompatible Tibased metal-organic framework for $\mathrm{pH}$-responsive drug delivery, Mater. Lett., 225, 142-144.

[9] Gao, X., Cui, R., Zhang, M., and Liu, Z., 2017, Metalorganic framework nanosheets that exhibit $\mathrm{pH}-$ controlled drug release, Mater. Lett., 197, 217-220.

[10] Wang, J., Wang, J., Zhang, M., Li, S., Liu, R., and Li, Z., 2020, Metal-organic frameworks-derived hollowstructured iron-cobalt bimetallic phosphide electrocatalysts for efficient oxygen evolution reaction, J. Alloys Compd., 821, 153463.

[11] Wu, Q., Siddique, M.S., and Yu, W., 2021, Ironnickel bimetallic metal-organic frameworks as bifunctional Fenton-like catalysts for enhanced adsorption and degradation of organic contaminants under visible light: Kinetics and mechanistic studies, J. Hazard. Mater., 401, 123261.

[12] Kirchon, A., Zhang, P., Li, J., Joseph, E.A., Chen, W., and Zhou, H. C., 2020, Effect of isomorphic metal substitution on the Fenton and photo-Fenton degradation of methylene blue using Fe-based metalorganic frameworks, ACS Appl. Mater. Interfaces, 12 (8), 9292-9299.

[13] Cai, X., Lin, J., and Pang, M., 2016, Facile synthesis of highly uniform Fe-MIL-88B particles, Cryst. Growth Des., 16 (7), 3565-3568.

[14] Ma, M., Bétard, A., Weber, I., Al-Hokbany, N.S., Fischer, R.A., and Metzler-Nolte, N., 2013, Ironbased metal-organic frameworks MIL-88B and $\mathrm{NH}_{2-}$ MIL-88B: High-quality microwave synthesis and solvent-induced lattice 'breathing', Cryst. Growth Des., 13 (6), 2286-2291.
[15] Hou, S., Wu, Y.N., Feng, L., Chen, W., Wang, Y., Morlay, C., and Li, F., 2018, Green synthesis and evaluation of an iron-based metal-organic framework MIL-88B for efficient decontamination of arsenate from water, Dalton Trans., 47 (7), 2222-2231.

[16] Choi, S., Cha, W., Ji, H., Kim, D., Lee, H.J., and Oh, M., 2016, Synthesis of hybrid metal-organic frameworks of $\left\{\mathrm{Fe}_{\mathrm{x}} \mathrm{M}_{\mathrm{y}} \mathrm{M}_{1-\mathrm{x}-\mathrm{y}}\right\}$-MIL-88B and the use of anions to control their structural features, Nanoscale, 8 (37), 16743-16751.

[17] Nguyen, H.T.T., Dinh, V.P., Phan, Q.A.N., Tran, V.A., Doan, V.D., Lee, T., and Nguyen, T.D., 2020, Bimetallic $\mathrm{Al} / \mathrm{Fe}$ metal-organic framework for highly efficient photo-Fenton degradation of rhodamine B under visible light irradiation, Mater. Lett., 279, 128482.

[18] Sun, Q., Liu, M., Li, K., Han, Y., Zuo, Y., Chai, F., Song, C., Zhang, G., and Guo, X., 2017, Synthesis of $\mathrm{Fe} / \mathrm{M}(\mathrm{M}=\mathrm{Mn}, \mathrm{Co}, \mathrm{Ni})$ bimetallic metal-organic frameworks and their catalytic activity for phenol degradation under mild conditions, Inorg. Chem. Front., 4 (1), 144-153.

[19] Ahmed, M.A., Rady, K.S., El-Shokrofy, K.M., Arais, A.A., and Shams, M.S., 2014, The influence of $\mathrm{Zn}^{2+}$ ions substitution on the microstructure and transport properties of $\mathrm{Mn}-\mathrm{Zn}$ nanoferrites, Mater. Sci. Appl., 5 (13), 932-942.

[20] Zhang, S., Gao, H., Li, J., Huang, Y., Alsaedi, A., Hayat, T., Xu, X., and Wang, X., 2017, Rice husks as a sustainable silica source for hierarchical flowerlike metal silicate architectures assembled into ultrathin nanosheets for adsorption and catalysis, $J$. Hazard. Mater., 321, 92-102.

[21] Vuong, G.T., Pham, M.H., and Do, T.O., 2013, Direct synthesis and mechanism of the formation of mixed metal $\mathrm{Fe}_{2} \mathrm{Ni}$-MIL-88B, CrystEngComm, 15 (45), 9694-9703.

[22] Zhang, C., Ai, L., and Jiang, J., 2015, Solvothermal synthesis of MIL-53(Fe) hybrid magnetic composites for photoelectrochemical water oxidation and organic pollutant photodegradation under visible light, J. Mater. Chem. A, 3 (6), 3074-3081.

[23] Saigl, Z.M., 2021, Various adsorbents for removal of 
rhodamine B dye: A review, Indones. J. Chem., 21 (4), 1039-1056.

[24] Chiu, Y.H., Chang, T.F.M., Chen, C.Y., Sone, M., and
Hsu, Y.J., 2019, Mechanistic insights into photodegradation of organic dyes using heterostructure photocatalysts, Catalysts, 9 (5), 430. 